\title{
PENGKAYAAN MATERI BAGI KADER JUMANTIK YANG TERGABUNG DALAM TANGGAP BOCAH [TABO] DI KECAMATAN SLEMAN
}

\author{
Naris Dyah Prasetyawati ${ }^{1}$, Sigid Sudaryanto ${ }^{2}$, Muslikah $^{3}$, Wahyu Widyantoro ${ }^{4}$ \\ ${ }^{124}$ Poltekkes Kemenkes Yogyakarta, ${ }^{3}$ Puskesmas Sleman \\ Email: naris.dyahp@ poltekkesjogja.ac.id
}

\begin{abstract}
In Indonesia, dengue fever is a contagious disease that can not yet be assigned. Cases of dengue fever in the subdistrict of sleman in 2015 reached 28 cases. It takes an active role in the community in efforts to prevent dengue fever. One of the active roles in the prevention of DHF is through education of children. Through activities Tanggap Bocah (TABO) is expected to give education of prevention of dengue disease. The purpose of this activity is to form a small health cadre through TABO in Sleman Community Working Area. This activity uses the method with discussion, question and answer, and simulation. This learning media uses children's games by including environmental health materials, especially $3 \mathrm{M}$ plus movements. The results of this activity can invite and increase the awareness of children to the DBD control program can monitor larvae in the home environment. This activity is considered very effective so it requires improving the pattern of training both in terms of materials and other components so that it can continue in line with the development of information.
\end{abstract}

Keywords: TABO, DHF, Empowerment

\begin{abstract}
Abstrak Di Indonesia demam berdarah merupakan penyakit menular yang belum bisa diberntas. Kasus demam berdarah di kecamatan sleman pada tahun 2015 mencapai 28 kasus. Diperlukan peran aktif masyarakat dalam upaya pencegahan penyakit DBD. Salah satu peran aktif dalam pencegahan DBD ini melalui edukasi anak-anak. Melalui kegiatan Tanggap Bocah (TABO) diharapkan mampu meberikan edukasi pencegahan penyakit DBD. Tujuan dari kegiatan ini adalah membentuk kader kesehatan cilik melalui TABO di Wilayah Kerja Puskesmas Sleman. Kegiatan ini menggunakan metode dengan diskusi, tanya jawab, dan simulasi. Media pembelajaran ini menggunakan permainan anak dengan memasukan materi kesehatan lingkungan khususnya gerakan $3 \mathrm{M}$ plus. Hasil kegiatan ini mampu mengajak dan meningkatkan kepedulian anak-anak terhadap program pengendalian DBD yaitu mampu melakukan pemantauan jentik di lingkungan rumah.Kegiatan ini dinilai sangat efektif sehingga memerlukan peningkatan pola pelatihan baik dari segi materi maupun komponen lainnya sehingga dapat terus sejalan mengikuti perkembangan informasi.
\end{abstract}

Kata kunci : TABO, DBD, Pemberdayaan

\section{PENDAHULUAN}

Tahun 2016 terdapat jumlah kasus DBD sebanyak 204.171 kasus dengan jumlah kematian sebanyak 1.598 orang.Jumlah angka kesakitan dan kematian kasus DBD Tahun 2016 mengalami peningkatan dari tahun 2015. Provinsi DIY masih menempati periingkat lima besar angka kesakitan DBD di Indonesia.(Kementerian Kesehatan RI, 2017). Angka kasus DBD yang masih tinggi di Indonesia ini, karena belum efektifnya kewaspadaan pencegahan DBD. Sehingga perlu ditingkatkan peran juru pantau jentik (jumantik) untuk melakukan kewaspadaan dini mewabahnya DBD. (Pratamawati, 2012). Kasus DBD di Kecamatan Sleman pada tahun 2015 sebanyak 23 kasus, sedangkan pada Tahun 2016 sampai dengan bulan Februari sebanyak 8 kasus. Angka bebas jentik pada Tahun 2015 mencapai 94\% sedangkan pada Februari Tahun 2016 mencapai 85\%. Angka kejadiannya tersebar hampir merata di 4 Desa dari 5 Desa yang berada di wilayah kerja Puskesmas Sleman. (Sleman, 2016)

Peran Puskesmas dalam hal pengendalian penyakit DBD hanya sebagai pembimbing dan motivator sehingga masyarakatlah yang harus aktif menciptakan lingkungan yang sehat disekitar mereka. Pengendalian DBD tidak hanya dapat dilakukan dengan tindakan kuratif tetapi harus didukung kegiatan preventif dan promotif. Pelaksanaan pemantauan jentik berkala merupakan salah satu cara preventif yang cukup baik untuk memonitoring keberadaan larva aedes sp yang merupakan vektor DBD.

Berbagai upaya yang telah dilakukan untuk mengendalikan angka kejadian penyakit DBD dan persebaran kasusnya, antara lain: surveilan penderita baik di rumah sakit maupun di rumah penderita, penyuluhan oleh petugas maupun kader, pelatihan pemantau jentik, penyebaran informasi dengan media leaflet, brosur, poster dan spanduk. Salah satu upaya yang dilakukan untuk mengendalikan dan menurunkan angka 
kejadian penyakit DBD dengan melakukan pelatihan pemantauan jentik berkala yang melibatkan anak-anak usia sekolah dasar sebagai pelakunya.

Tanggap Bocah (TABO) adalah upaya inovatif pencegahan DBD berbasis masyarakat dengan memilih anak-anak sebagai mitra kerja dalam upaya pencegahan DBD, sebagai usaha kaderisasi dan pembelajaran PHBS sejak usia dini. Dalam kegiatan ini anak-anak usia dini dilibatkan sebagai juru pemantau jentik (JUMANTIK) yang setiap minggunya mendatangi rumah warga untuk memeriksa keberadaan jentik di bak penampungan air atau tempat-tempat yang memungkinkan jentik nyamuk hidup dan berkembang biak.

Program TABO di Puskesmas Sleman dimulai pada tahun 2010 di Dusun Ganjuran ini membuahkan hasil. Kasus DBD menurun dan Angka Bebas Jentik (ABJ) meningkat. Tahun 2009 kasus DBD di dusun Ganjuran 3 kasus, menurun menjadi 1 kasus pada tahun 2010 dan tidak ada kasus pada tahun 2011. Sedangkan ABJ tahun 2009, 2010 dan 2011 berturut-turut sebesar 95\%, 96\% dan 96\%. Dengan keberhasilan tersebut, maka diharapkan program TABO akan semakin berkembang dan dusun binaan semakin banyak pula. (Puskesmas Sleman, 2016)

Tujuan dari kegiatan Pengabdian masyarakat ini adalah membuat anak-anak sadar sedini mungkin untuk menjaga kesehatan lingkungan di sekitarnya, menjadikan anak-anak terbiasa menerapkan Perilaku Hidup Bersih dan Sehat (PHBS) sedini mungkin dan sebagai salah satu upaya untuk menurunkan angka kejadian DBD di wilayah Kecamatan Sleman.

\section{METODE PELAKSANAAN}

Dalam pelaksanaannya dilakukan berbagai macam kegiatan untuk mencapai tujuan pengabdian masyarakat. Dimulai dengan koordinasi dengan pengelola Program dan penangungjawab kegiatan, kader dan tokoh masyarakat. Pada tahapan ini dilakukan koordinasi dengan petugas Puskesmas Sleman yang menangani kegiatan Tanggap Bocah. Tanggap Bocah di selenggarakan sejalan dengan Program 3 M Plus yaitu Menguras, Menutup, Mengolah barang bekas dan memantau jentik, Pemberian Abate, TABO melibatkan anak usia sekolah SD dan SMP dengan didampingi Pendamping kader Remaja dan kader Dewasa. Secara struktural tersendiri TABO tidak memiliki organisasi. Akan tetapi TABO berlindung di bawah Puskesmas Sleman. Secara struktural tampak bahwa TABO adalah perpanjangan tangan dari Puskesmas Sleman dengan lintas koordinasi kecamatan. TABO secara anggaran pelaksanaannya menggunakan anggaran bersama dari bidang kesehatan Kecamatan, Desa dan bidang UKM Puskesmas Sleman. TABO tidak bergerak sendiri melainkan di bawah pengawasan kader kesehatan dewasa. Secara langsung kader kesehatan dewasa bertanggung jawab kepada Puskesmas Sleman dan Kecamatan. Struktur ini merupakan struktur standar di tiap TABO yang disahkan melalui SK Kepala Desa.

Sasaran kegiatan ini adalah anggota TABO di Kecamatan Sleman sejumlah 50 Orang anak. Mengingat banyaknya anggota TABO, maka pemilihan peserta dilakukan oleh petugas Puskesmas dengan memperhatikan keterwakilan dari setiap lokasi. Kegiatan pengabdian masyarakat dilaksanakan di wilayah kerja Puskesmas Sleman. Mengambil tempat di ruang terbuka sehingga anak-anak lebih nyaman dalam menerima materi. Pada kegiatan pengabdian masyarakat kali ini diputuskan dilakukan di Beteng Pisangan Sleman Yogyakarta, dilakukan secara outdoor di ruang terbuka agar anak-anak dapat mengeksplorasi keaktifan mereka.

Pelaksanaan kegiatan dengan diskusi, tanya jawab, simulasi dan permainan menggunakan media belajar ular tangga. Media pembelajaran ini dirancang dengan memasukkan materi tentang lingkungan dan kegiatan seharihari yang berhubungan dengan kebiasaan untuk menjaga diri dan lingkungan, dilengkapi dengan gambar yang diharapkan anak-anak akan lebih tertarik untuk memainkannya dan pada jangka panjang diharapkan bisa menerapkan dalam kegiatan sehari-hari.

\section{HASIL DAN PEMBAHASAN}

Kegiatan pengabdian masyarakat ini merupakan kerjasama dari Jurusan Kesehatan Lingkungan Poltekkes Kemenkes Yogyakarta dengan Puskesmas Sleman sebagai mitra kerja untuk melakukan kegiatan tri dharma perguruan tinggi. Pelaksanaan kegiatan yang dilakukan, yaitu :

Kegaitan ini dilaksanakan pada Hari Sabtu Tanggal 12 Agustus 2017. Kegiatan diawali dengan Bina Suasana. Perkenalan diawali dengan bina suasana yang dipandu oleh Ibu Muslikah, SST dan kader, diawali menyanyikan Mars TABO oleh semua peserta. 


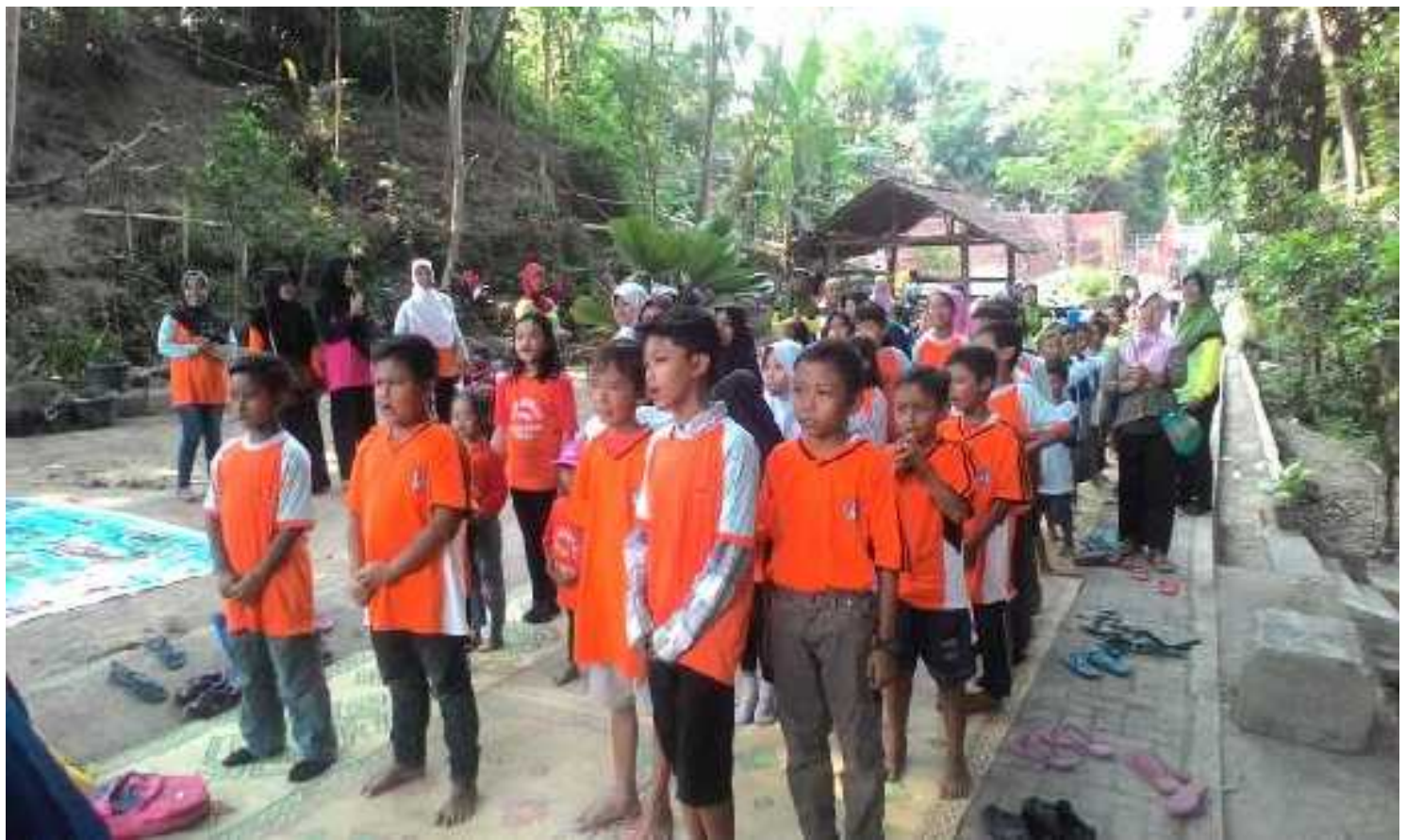

Gambar 1. Peserta dan Kader menyanyikan lagu Mars TABO

Pemberian materi berupa power point dan video tidak jadi dilakukan karena kondisi di lapangan tidak memungkinkan membawa layar. Sehingga dilakukan dengan game edukatif berupa pertanyaan dan materi tentang $\mathrm{DBD}$, CTPS, PHBS sekaligus sebagai pre test. Pemberian materi selanjutnya melalui metode peragaan alat permainan edukatif "Ular Tangga Germas”. Penggunaan alat peraga pendidikan ini bertujuan untuk: a. Mengenalkan kepada anak-anak tentang Gerakan Masyarakat Hidup Sehat (GERMAS) sedini mungkin melalui media permainan yang akrab dengan lingkungan anak

b. Membiasakan anak-anak mengaplikasikan kegiatan yang berhubungan dengan PHBS dan GERMAS sedini mungkin

c. Menumbuhkan rasa kebersamaan diantara sesama anak dan lingkungannnya

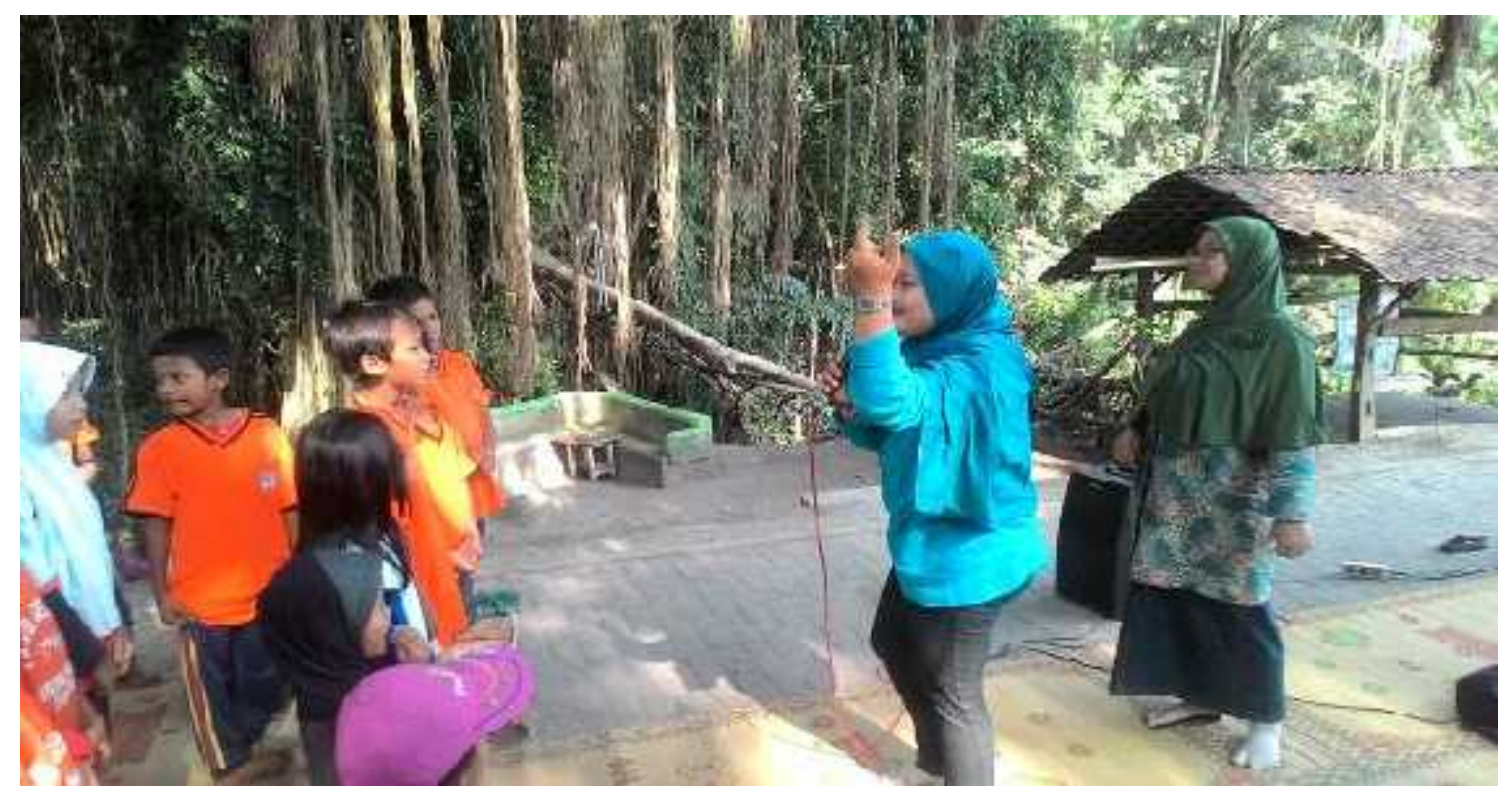

Gambar 2 . Penyampaian materi oleh Poltekkes dan Puskesmas Sleman 


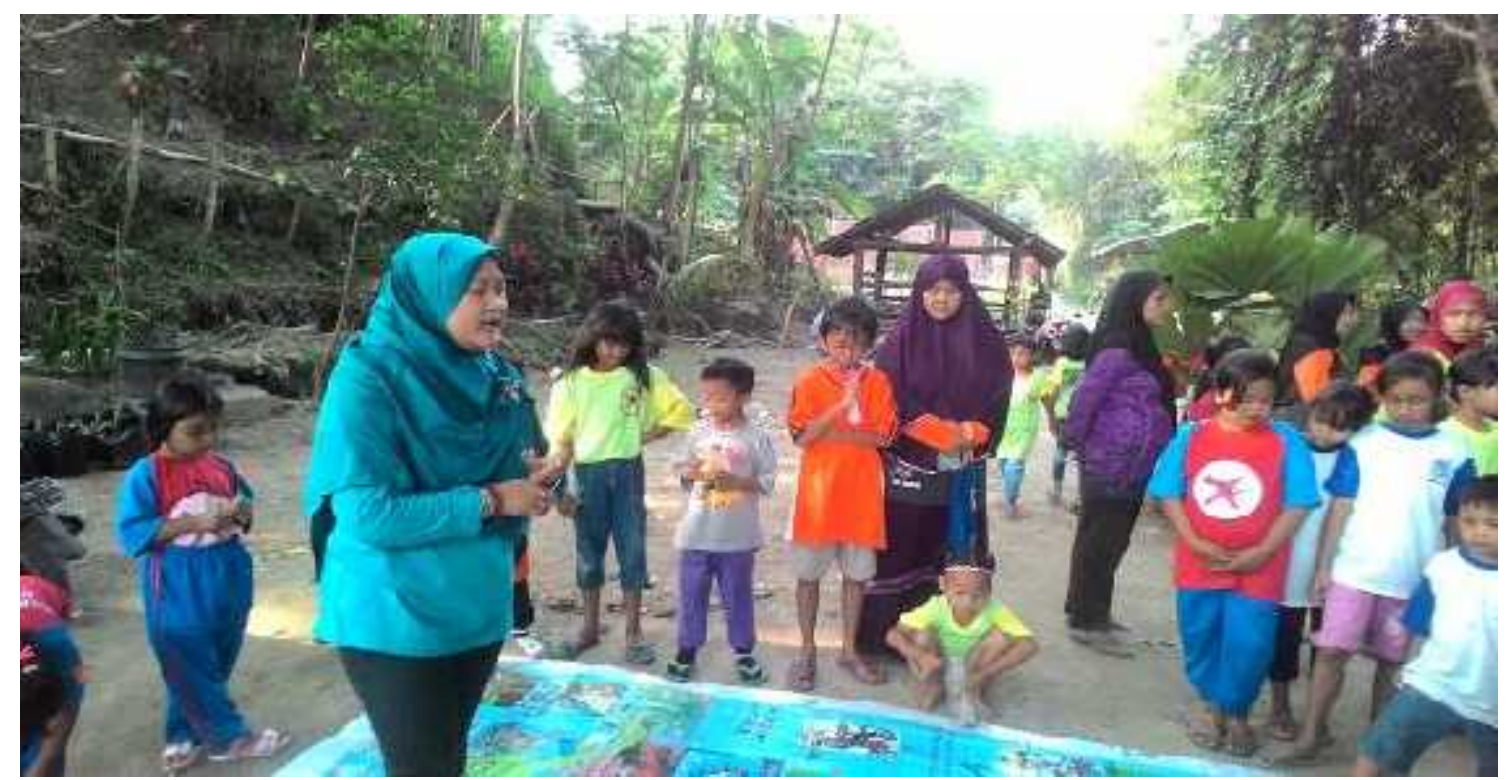

Gambar 3 Narasumber sebagai instruktur permainan menjelaskan prosedur permainan kepada peserta

Cara melakukan permainan ini hampir sama pada permainan tradisional ular tangga, akan tetapi ukuran yang digunakan lebih besar daripada ular tangga yang biasa. Tahapan permainan ini, yaitu :

1) Dalam satu kali permainan dibagi dalam 3 sampai 5 tim

2) Dalam satu kali permainan terdapat wasit/juri atau instruktur yang bertugas menjelaskan setiap pesan yang ada dalam kotak-kotak serta mengawal fair play dalam permainan ini

3) Setiap tim terdiri dari 2-3 orang

4) Ketua tim menunjuk 1 orang perwakilan untuk menjadi peraga $\rightarrow$ yang akan berpindah-pindah kotak sesuai dengan angka yang muncul pada dadu yang dilempar

5) Setelah diundi dan keluar angka pada dadu yang dilempar peraga tersebut berpindah sesuai kotaknya $\rightarrow$ membaca perintah yang ada di kotak tersebut $\rightarrow$ anggota tim lain atau peraga sendiri melakukan simulasi atau peragaan yang diminta oleh kota yang diinjak tersebut

6) Tim yang bisa mencapai FINISH terlebih dahulu adalah pemenangnya

7) Simulasi : Seorang A melempar dadu dan keluar angka 4 maka B sebagai anggota tim harus berjalan 4 langkah sampai kotak $4 \rightarrow$ dalam kotak 4 terdapat pesan "AKU MEMELIHARA KUKU SEHINGGA SELALU PENDEK DAN BERSIH" $\rightarrow$ juri/instruktur menjelaskan kepada semua peserta pentingnya memelihara kebersihan kuku dan melihat bagaimana kuku si B sebagai peraga 


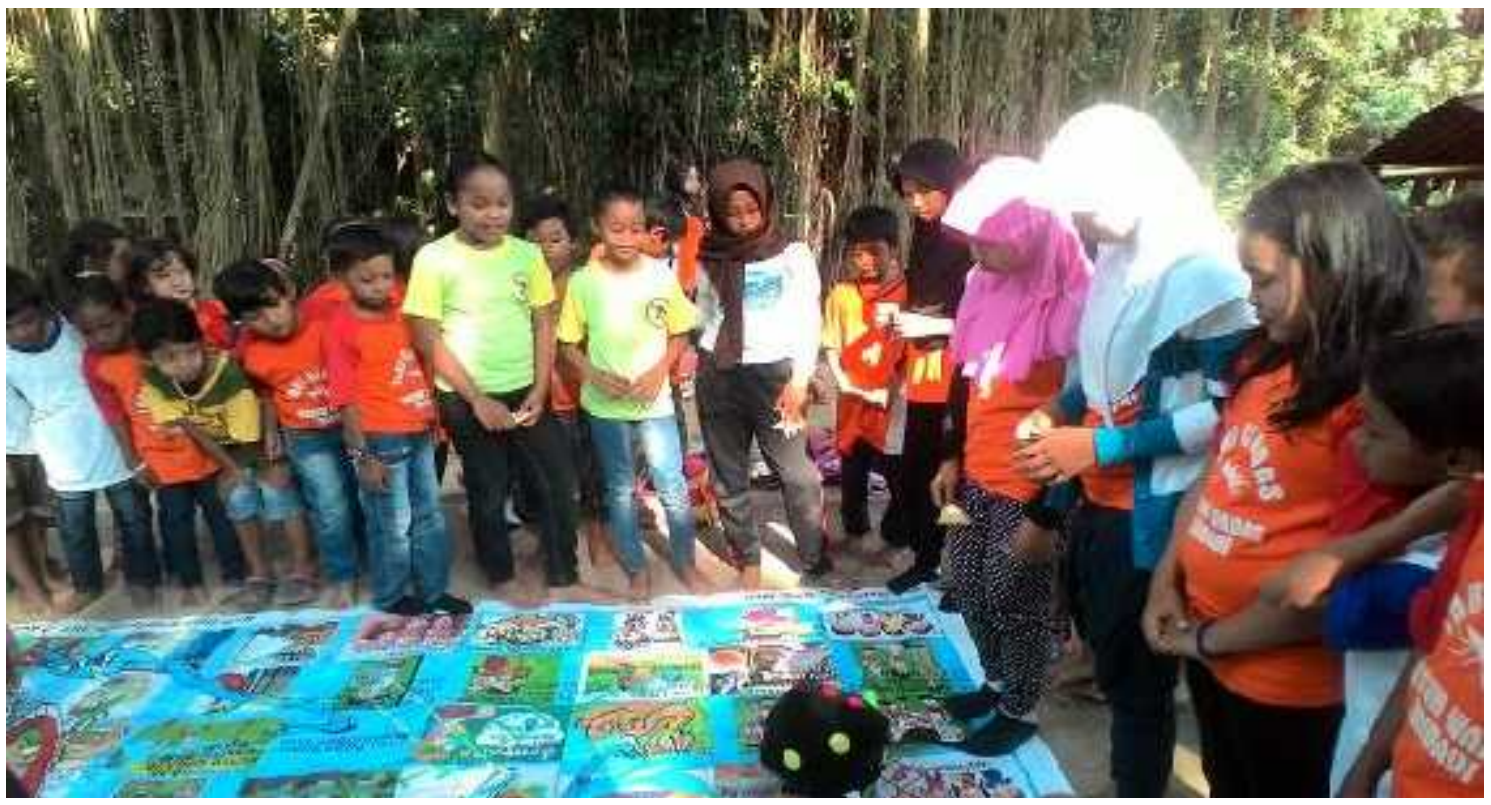

Gambar 4. Peserta Melakukan Permainan Ular Tangga GERMAS

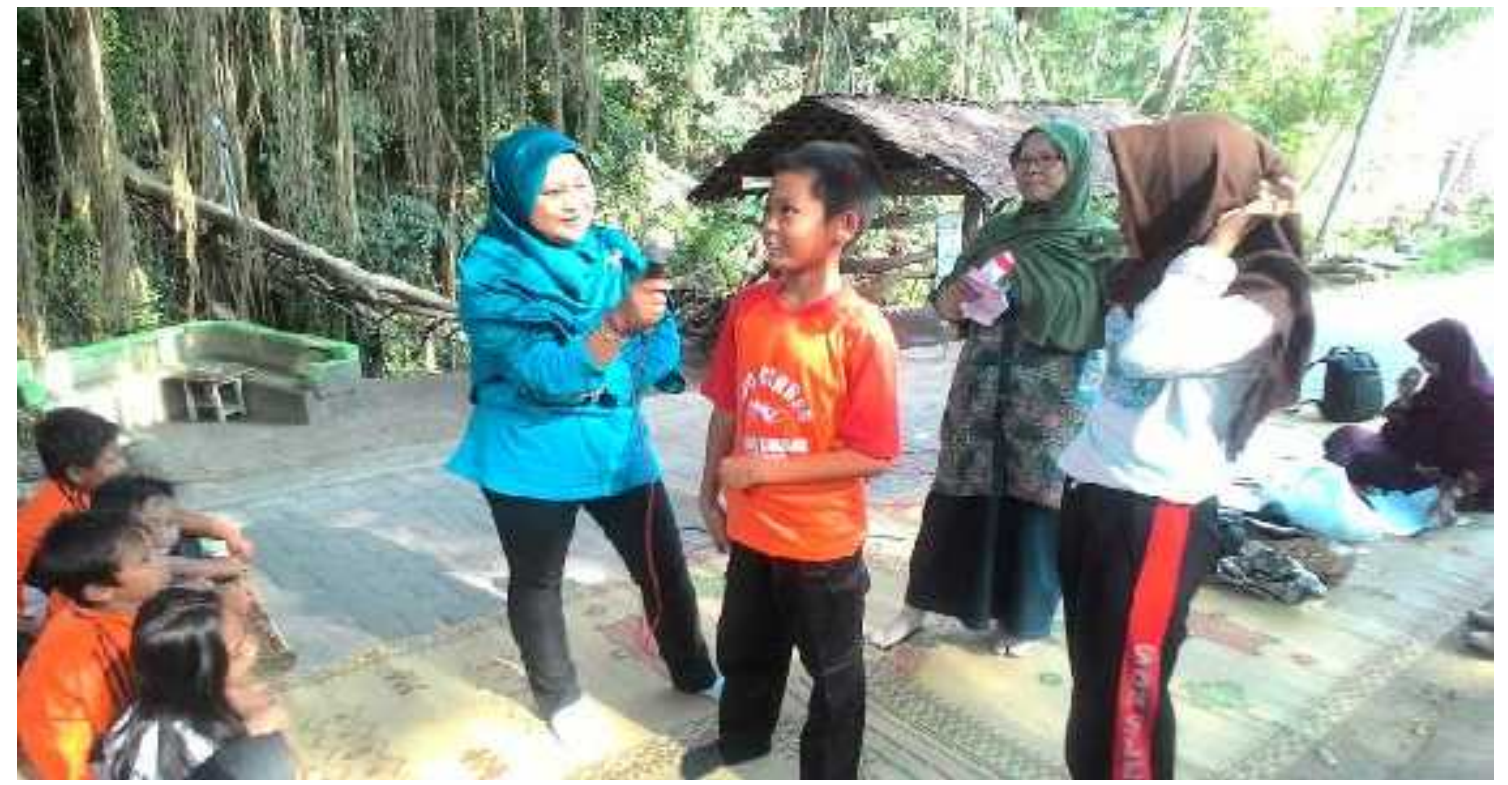

Gambar 5. Interaksi dengan Beberapa Peserta Untuk Review Materi (Post Test)

Kegiatan Penutup dilakukan setelah beristirahat. Kegiatan pengabdian masyarakat ini diakhiri dengan post test berupa pemberian pertanyaan dan tantangan untuk memperagakan suatu kegiatan berdasarkan yang sudah dilakukan dalam permainan ular tangga tersebut. Peserta yang dapat melakukan dengan tepat mendapatkan hadiah berupa sabun atau serbet untuk cuci tangan.

Antusiasme anak-anak sangat baik dalam kegiatan ini baik ketika menerima materi, permainan maupun quiz untuk pre dan post test nya. Pemberian bahan kontak berupa senter dan buku materi diberikan secara simbolis kepada perwakilan peserta.

Kegiatan Monitoring dan Evaluasi dilakukan dengan melakukan diskusi antara petugas Puskesmas dan Kader dewasa yang menjadi pendamping setiap kelompok TABO yang dikirimkan sebagai peserta. Berdasarkan hasil sosialisasi di lapangan beberapa masukan yang diberikan untuk alat peraga pendidikan ini, antara lain:

a. Tulisan dalam kotak ular tangga kurang terlihat karena perpaduan warna yang mencolok 
b. Gambar ular terlalu mendominasi $\rightarrow$ digambarkan biasa saja misalnya ular weling

c. Permainan dilakukan maksimal oleh 5 kelompok agar durasi waktu tidak terlalu lama

d. Semua materi sudah masuk didalamnya : anak diharapkan lebih suka dan paham tentang kondisi lingkungan sekitarnya

e. Alat peraga pendidikan ini mendukung kegiaran $\mathrm{TABO} \rightarrow$ sehingga jumlahnya diharapkan bisa ditingkatkan agar bisa digunakan untuk kegiatan harian dan masuk dalam rencana kegiatan untuk penambahan materi bagi TABO

Peran jumantik sangat penting dalam pencegahan penyakit DBD. Hal ini penting untuk melakukan kewaspadaan dini mewabahnya penyakit DBD dimasyarakat. TABO sebagai inovasi pemberdayaan masyarkat dengan meningkatkan peran anak-anak dalam mewaspadai terhadap keberadaan jentik di lingkungan mereka. (Syatriani, Puji, \& Susilowati, 2009)

TABO merupakan bagian dari jumantik yang terus diberdayakan oleh Puskesmas Sleman. Peranan Jumantik dalam meningkatkan angka bebas Jentik dinilai efektif di daerah endemis. (Subaris, Subiyanto, Kartono, \& Lestary, 2016). Melalui pemberdayaan TABO ini mampu melakukan pemantauan jentik nyamuk di sekitar rumah mereka didampingi dengan kader kesehatan di Dusun masing-masing.

\section{SIMPULAN DAN SARAN}

Kesimpulan dari kegiatan ini, antara lain : alat peraga pendidikan berupa ular tangga ini sangat familiar bagi anak-anak sehingga mudah untuk mengenalkan dan menggunakannya. Materi tentang kesehatan lingkungan dan lainnya mudah dipahami dan diingat oleh anak-anak. Anak-anak mudah memahami peragaan tentang CTPS dan kegiatan yang ada dalam materi dalam ular tangga tersebut

Saran yang dapat diberikan kepada institusi (Puskesmas), antara lain : Melakukan sosialisasi kembali dengan kelompok TABO yang lain sehingga banyak anggota TABO yang akan terpapar materi dalam permainan ini. Menyelenggarakan kompetisi permainan ini antar kelompok TABO yang dapat juga digunakan sebagai sarana untuk pemantauan keberhasilan program yang telah dilakukan

\section{DAFTAR PUSTAKA}

Kementerian Kesehatan RI. (2017). Profil Kesehatan Indonesia Tahun 2016. Retrieved from

http://www.depkes.go.id/resources/downloa d/pusdatin/profil-kesehatan-

indonesia/Profil-Kesehatan-Indonesia2016.pdf

Pratamawati, D. A. (2012). Peran Juru Pantau Jentik dalam Sistem Kewaspadaan Dini Demam Berdarah Dengue di Indonesia. Kesmas: National Public Health Journal, 6(6), 243-248. Retrieved from http://jurnalkesmas.ui.ac.id/kesmas/article/v iew/76/77

Puskesmas Sleman. (2016). Profil Tanggap Bocah (TABO) Tahun 2016. Yogyakarta.

Sleman, P. (2016). Profil Puskesmas Sleman Tahun 2016. Yogyakarta.

Subaris, H., Subiyanto, S., Kartono, D. T., \& Lestary, E. (2016). International journal of public health science. International Journal of Public Health Science (IJPHS) (Vol. 5). Inst. of Advanced Engineering and Science. Retrieved from http://iaescore.com/journals/index.php/IJPH S/article/view/4772/3797

Syatriani, S., Puji, E., \& Susilowati, A. (2009). Partisipasi Masyarakat Menanggulangi Lingkungan Demam Berdarah Dengue di Kecamatan Rappocini Kota Makasar. Kesmas: National Public Health Journal, 3(5), 219-223. Retrieved from http://jurnalkesmas.ui.ac.id/kesmas/article/v iew/213/213 